\title{
Effect of Closure of a Local Safety-Net Hospital on Primary Care Physicians' Perceptions of Their Role in Patient Care
}

Kara Odom Walker, MD, MPH, MSHS $^{1}$

Robin Clarke, $M D^{2}$

Gery Ryan, $P b D^{3}$

Arleen F. Brown, MD, PbD

'Department of Family \& Community Medicine, University of California-San Francisco, San Francisco, California

${ }^{2}$ RAND, Santa Monica, California

${ }^{3}$ Robert Wood Johnson Clinical Scholars Program, University of California-Los Angeles, Los Angeles, California

${ }^{4}$ Division of General Internal Medicine and Health Services Research, University of California-Los Angeles, Los Angeles, California

im

MORE ONLINE

www.annfammed.org
Conflicts of interest: authors report none.

\section{CORRESPONDING AUTHOR}

Kara Odom Walker, MD, MPH, MSHS 995 Potrero Ave W 83

San Francisco, CA 94110

odomwalkerk@fcm.ucsf.edu

\begin{abstract}
PURPOSE We examined how the closure of a large safety-net hospital in Los Angeles County, California, affected local primary care physicians.

METHODS We conducted semistructured interviews with 42 primary care physicians who practiced in both underserved and nonunderserved settings in Los Angeles County. Two investigators independently reviewed and coded transcripts. Three investigators used pile-sorting to sort the codes into themes.

RESULTS Overall, 28 of 42 physicians (67\%) described some effect of the hospital closure on their practices. Three major themes emerged regarding the impact of the closure on the affected physicians: (1) reduced local access to specialist consultations, direct hospital admissions, and timely emergency department evaluation; (2) more patient delays in care and worse health outcomes because of poor patient understanding of the health care system changes; and (3) loss of colleagues and opportunities to teach residents and medical students.
\end{abstract}

CONCLUSIONS Physicians in close proximity to the closed hospital-even those practicing in nonunderserved settings-reported difficulty getting their patients needed care that extended beyond the anticipated loss of inpatient services. There is a need for greater recognition of and support for the role primary care physicians play in coordinating care; promoting continuity of care; and informing patients, clinic administrators and policy makers about system changes during such transitions.

Ann Fam Med 2011;9:496-503. doi:10.1370/afm.1317.

\section{INTRODUCTION}

$\mathrm{P}$ rior studies on the effects of safety-net hospital closure have shown that minority, elderly, and uninsured populations are subsequently at risk for poorer access to care and health outcomes. ${ }^{1-4}$ To our knowledge, few studies have assessed the impact of such closures on local primary care clinicians. ${ }^{5,6}$ In recent decades, closures of large urban public hospitals have occurred in Philadelphia, Pennsylvania, Washington, DC, and New York City, but there have been few studies of the impact of closure on outpatient settings. ${ }^{78}$ In August 2007, Martin Luther King (MLK) Hospital in South Los Angeles, a publicly funded teaching hospital operated by Los Angeles County, was closed because of financial pressures and accreditation challenges. The closure resulted in the loss of 450 acute-care hospital beds and an extremely busy emergency department and trauma center. The transition plan involved transferring patient care to regional county facilities and maintaining a multispecialty ambulatory care clinic in its place ${ }_{i}$ however, few practicing primary care physicians were included in this planning process. In addition, there was an impact on faculty practices located at the hospital, and medical student and resident teaching was dramatically changed after the closure of this major teaching site. 
As community stakeholders planned for rebuilding the health infrastructure in South Los Angeles, the challenges faced by the physicians and community clinics became increasingly apparent. For this reason and because studies have shown how primary care physicians can be part of interventions to improve poor health care quality, our community advisory board (CAB) decided to explore the physicians' perspectives on the hospital's closure. ${ }^{9-11}$ We used community input to conduct a qualitative study of the physicians' perceptions of the closure. Our objectives were (1) to describe the impact of the closure on the physicians and their practices and (2) to examine their response to changes resulting from the closure.

\section{METHODS}

\section{Study Development}

We formed a 7-member CAB composed of researchers, medical educators, physician leaders, and community clinic administrators who collaborated on study design, participant recruitment, and dissemination. The advisory board was convened from separate entities that were concerned about physician supply in South Los Angeles. Each representative had a particular contribution to future strategies to address physician workforce issues in the coming months and years after hospital closure. Although this particular board did not have an independent function, they have worked together on similar advocacy issues in the past. The CAB helped develop the research question, interview questions, and recruitment strategy. They reviewed the final interview guide and helped to test the questions before use. They reviewed initial themes midway through study interviews and helped to develop the final themes. $\mathrm{CAB}$ members also brought the findings back to their respective organizations

We recruited 42 primary care physicians with a current clinical practice of at least 20 hours a week for 1-hour semistructured interviews. We did purposeful quota sampling of physicians by race/ethnicity and equally included those from underserved and nonunderserved settings. The practice setting was defined as underserved if it was a federally qualified community health center or clinic designated within a Health Profession Shortage Area by the Health Resources and Service Administration. We also categorized physicians by distance to the closed hospital using a 12-mile cutoff because this is a commonly used estimate of the local service area in the Los Angeles County public health systems.

We used a referral-based sampling technique, similar to snowball sampling, that started with the CAB for the first wave of study enrollment (Figure 1). To mitigate selection bias, we limited the number of referrals to fewer than 4 per $C A B$ member or participant and excluded duplicate names. Of the 26 individuals referred by the $\mathrm{CAB}, 17$ physicians were interviewed based on responses and eligibility. Referrals from these 17 study participants generated a second wave of 24 individuals, 18 of whom were eligible and agreed to participate. In the third wave, we interviewed 7 physicians who fulfilled the study criteria. Each potential participant was contacted by telephone, e-mail, or both and given up to 6 weeks to decline participation or schedule an interview. Overall, of 57 individuals referred for open interview slots, 4 were ineligible and $11 \mathrm{did}$ not respond to requests for interviews through e-mail or telephone. Interviews were conducted from March through September 2008, between 6 and 13 months after the hospital's closure.

\section{Study Protocol}

Interviewers were trained in the use of qualitative interviewing techniques and used the aforementioned interview guide (Supplemental Appendix 1, available online at http://www.annfammed.org/content/9/6/496/suppl/DC1), which contained openended questions and several time-point prompts, as well as a short demographic questionnaire. During the 1-hour semistructured interviews, we asked the physicians open-ended questions about how the closure of MLK Hospital affected their practices, using standardized probes to investigate the impact of the closure on admitting privileges, specialty care, elective surgery,

\section{Figure 1. Recruitment process.}

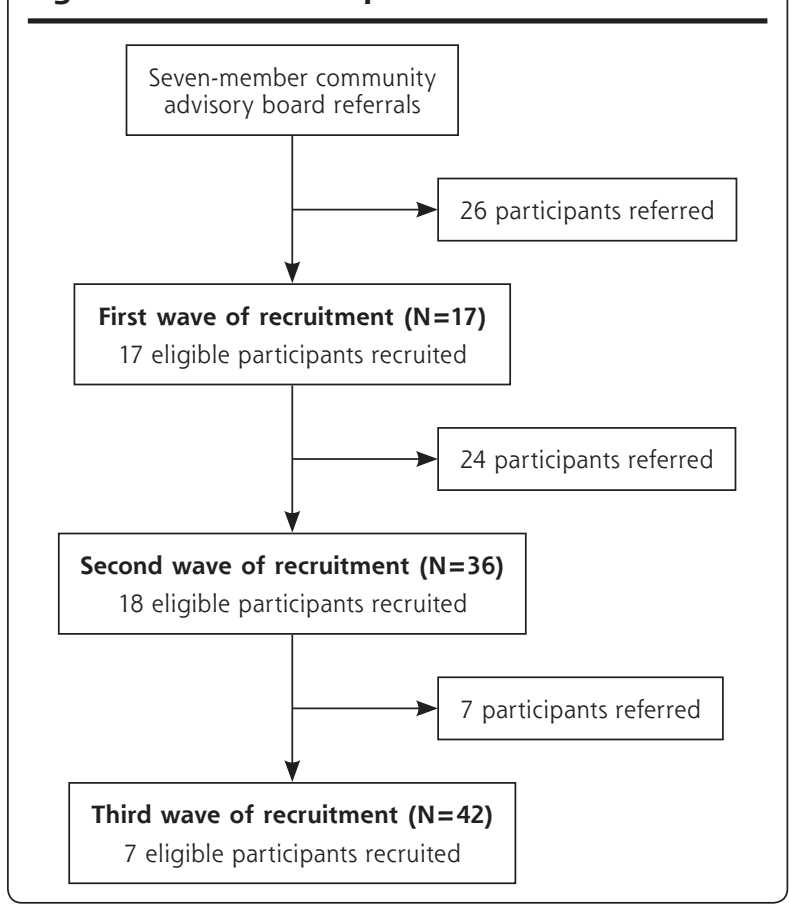


teaching, emergency care, and other issues not specifically covered by our questions. The RAND Institutional Review Board approved the study protocol.

\section{Data Analysis}

The digitally recorded interviews were professionally transcribed verbatim and the transcripts were reviewed by the interviewer for accuracy. Two investigators (K.O.W. and R.C.) independently analyzed each transcript using standard qualitative contentanalysis methods to identify meaningful quotes. Specifically, transcripts were read several times in an iterative process to identify recurring concepts that represented the overall effect of hospital closure on primary care practices. These concepts were signified by codes that were used to label quotations that represented discrete thoughts. After independently coding transcripts, between-coder comparisons were completed and the codes were compiled into a revised codebook $(\kappa=82.6 \%)$.

We next categorized the coded quotes by pile-sorting them into larger categories or subthemes. Within each grouping, we selected statements representative of the subthemes based on relevance and clarity of expression. Three investigators (K.O.W., R.C., and A.F.B.) then reviewed the subthemes for relevancy and consistency as the overarching themes emerged on hospital closure effects on physicians' practices. We then reviewed the themes with the $\mathrm{CAB}$ and agreed on the overarching categories. We compared the responses of physicians who practiced in underserved settings in Los Angeles County with those of physicians who practiced in nonunderserved settings. We also compared responses between those who practiced 12 miles or less from the hospital and those who practiced farther away. Atlas.ti software version 5.2 (Atlas. ti Scientific Software Development, Berlin, Germany) was used to facilitate data management and analysis.

\section{RESULTS}

\section{Demographics}

The 42 participating physician ranged in age from 31 to 73 years, with a mean age of 48 years (SD 12); $45 \%$ were female (Table 1 ). By specialty, $48 \%$ were in fam- ily medicine, $31 \%$ were in internal medicine, $17 \%$ were in pediatrics, and $5 \%$ were in other primary care fields. The mean distance to MLK Hospital was considerably closer for physicians in underserved settings (9.1 vs 19.4 miles). Overall, two-thirds (28 of 42) of the physicians described an effect of the closure (Figure 2). The vast majority of physicians in underserved settings, 19 of $21(90 \%)$, reported that the closure affected their practice, but so did a sizable minority of physicians in nonunderserved settings, 9 of 21 (43\%).

\section{Central Themes}

From the comments of the 28 primary care physicians who indicated that the hospital closure had affected their practices, we identified 3 overarching themes: (1) changes
Table 1. Characteristics of Participating Primary Care Physicians

\begin{tabular}{|c|c|c|c|}
\hline \multirow[b]{2}{*}{ Characteristic } & \multirow[b]{2}{*}{$\begin{array}{c}\text { Total } \\
(\mathrm{N}=42)\end{array}$} & \multicolumn{2}{|c|}{ Practice Setting ${ }^{a}$} \\
\hline & & $\begin{array}{l}\text { Underserved } \\
\quad(n=21)\end{array}$ & $\begin{array}{l}\text { Nonunderserved } \\
(n=21)\end{array}$ \\
\hline Age, y & $48 \pm 12$ & $50 \pm 14$ & $46 \pm 10$ \\
\hline Female & $45(19)$ & $43(9)$ & $48(10)$ \\
\hline \multicolumn{4}{|l|}{ Marital status } \\
\hline Married & $60(25)$ & $57(12)$ & $62(13)$ \\
\hline Single & $19(8)$ & $29(6)$ & $10(2)$ \\
\hline Divorced & $10(4)$ & $10(2)$ & $10(2)$ \\
\hline Other & $11(5)$ & $4(1)$ & $18(4)$ \\
\hline \multicolumn{4}{|l|}{ Income distribution } \\
\hline$<\$ 100 K$ & $7(3)$ & $5(1)$ & $10(2)$ \\
\hline$\$ 100 K-\$ 149 K$ & $26(11)$ & $24(5)$ & $28(6)$ \\
\hline$\$ 150 K-\$ 199 K$ & $33(14)$ & $38(8)$ & $28(6)$ \\
\hline$\$ 200 K-\$ 249 K$ & $21(9)$ & $19(4)$ & $24(5)$ \\
\hline$\geq \$ 250 K$ & $12(5)$ & $14(3)$ & $10(2)$ \\
\hline \multicolumn{4}{|l|}{ Medical education } \\
\hline California & $69(29)$ & $71(15)$ & $67(14)$ \\
\hline Public & $76(32)$ & $81(17)$ & $71(15)$ \\
\hline Residency training in California & $69(29)$ & $67(14)$ & $71(15)$ \\
\hline \multicolumn{4}{|l|}{ Specialty distribution } \\
\hline Family medicine & $48(20)$ & $52(11)$ & $43(9)$ \\
\hline Internal medicine & $31(13)$ & $19(4)$ & $43(9)$ \\
\hline Pediatrics & $17(7)$ & $24(5)$ & $9(2)$ \\
\hline Other primary care & $5(2)$ & $5(1)$ & $5(1)$ \\
\hline \multicolumn{4}{|l|}{ Practice setting } \\
\hline Staff model HMO/Kaiser & $26(11)$ & $10(2)$ & $43(9)$ \\
\hline Community/public clinic & $31(13)$ & $62(13)$ & $0(0)$ \\
\hline University & $21(9)$ & $10(2)$ & $33(7)$ \\
\hline Private practice & $21(9)$ & $19(4)$ & $24(5)$ \\
\hline $\begin{array}{l}\text { No. reporting they were } \\
\text { affected by closure }\end{array}$ & 28 & 19 & 9 \\
\hline $\begin{array}{l}\text { Distance from closed hospital, } \\
\text { miles }\end{array}$ & 14.2 & 9.1 & 19.4 \\
\hline No. of themes per physician & 1.97 & 3.0 & 1.67 \\
\hline \multicolumn{4}{|c|}{$\mathrm{HMO}=$ health maintenance organization.} \\
\hline \multicolumn{4}{|c|}{ Note: Values are expressed as number, mean $( \pm \mathrm{SD})$, or percent (no.). } \\
\hline \multicolumn{4}{|c|}{$\begin{array}{l}\text { a No statistically significant differences were seen between physicians in underserved and nonunder- } \\
\text { served settings, except for practice setting, using } \chi^{2} \text { tests }(P<.05) \text {. }\end{array}$} \\
\hline
\end{tabular}


to local and regional health care system capacity $_{i}$ (2) difficulty for patients in navigating the system of care; and (3) changes in workforce and training. Below, we report the most salient subthemes and metathemes along with selected representative quotations that exemplify the range of core topics, problems, and concerns (Table 2) and numbers of physicians who described each effect (Table 3).

Theme 1: Changes to Local and Regional Health Care System Capacity With the hospital's closure, physicians noted a marked decrease in the system's capacity. The subthemes that emerged were decreased access to specialists, inpatient care overcrowding, emergency department overcrowding, and difficulty with primary care linkages.

\section{Figure 2. Effects on physicians and development of themes.}

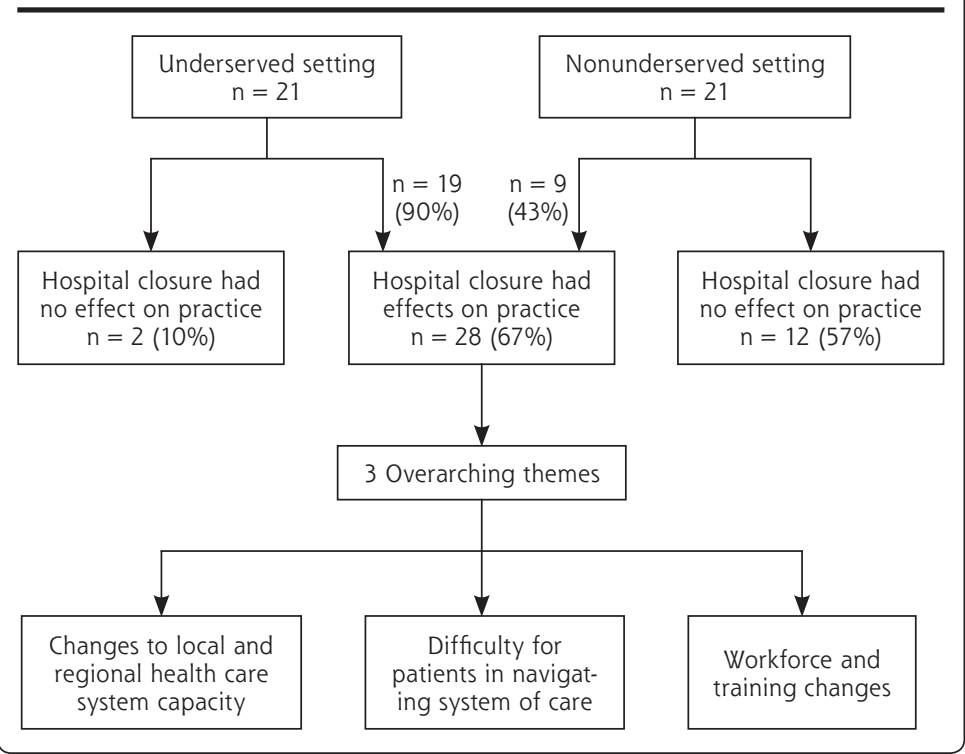

Table 2. Sample Quotations by Primary Care Physicians in Underserved and Nonunderserved Settings

\begin{tabular}{|c|c|c|}
\hline \multirow{2}{*}{$\begin{array}{l}\text { Theme and } \\
\text { Subtheme }\end{array}$} & \multicolumn{2}{|c|}{ Sample Quotations } \\
\hline & Physicians in Underserved Settings & Physicians in Nonunderserved Settings \\
\hline \multicolumn{3}{|c|}{ Changes to local and regional health care system capacity } \\
\hline $\begin{array}{l}\text { Inpatient care } \\
\text { over capacity }\end{array}$ & $\begin{array}{l}\text { "Now everybody has to be transported who needs to be admit- } \\
\text { ted, because we don't have any inpatient facilities per se." }\end{array}$ & - \\
\hline $\begin{array}{l}\text { Emergency } \\
\text { department } \\
\text { overcrowding }\end{array}$ & $\begin{array}{l}\text { "...we don't have emergency room, we only have the urgent care } \\
\text { that is very limited." }\end{array}$ & $\begin{array}{l}\text { "You're seeing more uninsured patients that are } \\
\text { affected.... They tend to be sicker because } \\
\text { they're not getting any care anywhere. You } \\
\text { know, an emergency room is an emergency } \\
\text { room." }\end{array}$ \\
\hline $\begin{array}{l}\text { Decreased access } \\
\text { to specialists }\end{array}$ & $\begin{array}{l}\text { "And even though the hospital here is now called a multiambula- } \\
\text { tory care center, especially in pediatrics, some of the specialty } \\
\text { services we were providing we're not providing anymore, } \\
\text { because they moved them out of the hospital." }\end{array}$ & - \\
\hline $\begin{array}{l}\text { Decreased access } \\
\text { to elective } \\
\text { surgery }\end{array}$ & $\begin{array}{l}\text { "I mean, even before closures, sometimes elective surgery, you'd } \\
\text { have to wait a year before you had your surgery, so I don't } \\
\text { know that it's worse than that now. I mean, that's pretty bad." }\end{array}$ & $\begin{array}{l}\text { "I said I didn't have access of some specialty and } \\
\text { somebody made the comment to me, well, you } \\
\text { can just refer them over to UCLA. I though, } \\
\text { what a naïve comment. Many of these people } \\
\text { don't have cars. They walked to the facility } \\
\text { because that was their community backstop." }\end{array}$ \\
\hline \multicolumn{3}{|c|}{ Difficulty for patients in navigating system of care } \\
\hline $\begin{array}{l}\text { Greater delays in } \\
\text { care }\end{array}$ & $\begin{array}{l}\text { "That's because they're coming to [clinic] into emergency care. } \\
\text { They're coming to us bleeding and they're coming to us where } \\
\text { they should actually be going } 911 \text { and going to actual emer- } \\
\text { gency rooms but they prefer to come to us lots of times." }\end{array}$ & $\begin{array}{l}\text { "...waiting times, so people are getting put off } \\
\text { longer and longer times before they actually } \\
\text { get authorized for surgical care. They just wait } \\
\text { longer and then they get sicker." }\end{array}$ \\
\hline $\begin{array}{l}\text { Poorer access and } \\
\text { lower quality } \\
\text { of care }\end{array}$ & $\begin{array}{l}\text { "The fact that [the hospital closed] is also going to affect in } \\
\text { terms of whether these people get their care. I mean where } \\
\text { are people going to go? So, it's going to be these 'safety-nets' } \\
\text { that actually take them. The problem is the safety-nets are } \\
\text { bursting...." }\end{array}$ & $\begin{array}{l}\text { "What we have seen has been a sharp increase in } \\
\text { our volume because with County services-not } \\
\text { just hospitals, but County services in general } \\
\text { being cut back-a lot of [patients] have a lot } \\
\text { fewer resources.... And there's fewer places for } \\
\text { them to go." }\end{array}$ \\
\hline \multicolumn{3}{|c|}{ Workforce and training changes } \\
\hline $\begin{array}{l}\text { Loss of train- } \\
\text { ing sites and } \\
\text { faculty }\end{array}$ & $\begin{array}{l}\text { "There's no teaching. Recently they cut off even teaching to } \\
\text { medical students." }\end{array}$ & $\begin{array}{l}\text { "The residents are maybe a little bit busier } \\
\text { because they're taking a few more patients... } \\
\text { the patients always present learning opportuni- } \\
\text { ties for the residents, so I don't think that it's a } \\
\text { negative thing." }\end{array}$ \\
\hline $\begin{array}{l}\text { Workforce } \\
\text { relocated }\end{array}$ & $\begin{array}{l}\text { "Then, when the hospital closed last summer, there was a huge } \\
\text { exodus. Charles Drew University's faculty, the practicing faculty } \\
\text { completely disappeared.... I don't think anybody appreciated... } \\
\text { how valuable that medical staff was." }\end{array}$ & - \\
\hline
\end{tabular}




\begin{tabular}{|c|c|c|c|c|c|}
\hline \multirow[b]{2}{*}{ Theme and Subtheme } & \multirow[b]{2}{*}{$\begin{array}{c}\text { Total } \\
(\mathrm{N}=42)\end{array}$} & \multicolumn{2}{|c|}{ Setting } & \multicolumn{2}{|c|}{ Distance } \\
\hline & & $\begin{array}{l}\text { Underserved } \\
\quad(n=21)\end{array}$ & $\begin{array}{l}\text { Nonunderserved } \\
\quad(n=21)\end{array}$ & $\begin{array}{l}\leq 12 \text { Miles } \\
(n=17)\end{array}$ & $\begin{array}{l}>12 \text { Miles } \\
(\mathrm{n}=25)\end{array}$ \\
\hline $\begin{array}{l}\text { Changes to local and regional health care system } \\
\text { capacity }\end{array}$ & 24 & 16 & 8 & 14 & 10 \\
\hline Within the local area & 16 & 12 & 4 & 11 & 5 \\
\hline Inpatient care over capacity & 5 & 4 & 1 & 3 & 2 \\
\hline Emergency department overcrowding & 4 & 4 & 0 & 4 & 0 \\
\hline Decreased access to specialists & 10 & 7 & 3 & 7 & 3 \\
\hline Decreased access to elective surgery & 5 & 5 & 0 & 4 & 1 \\
\hline Outside the local area & 15 & 8 & 7 & 9 & 6 \\
\hline Inpatient care over capacity & 7 & 4 & 3 & 3 & 4 \\
\hline Emergency department overcrowding & 10 & 5 & 5 & 7 & 3 \\
\hline Decreased access to specialists & 2 & 2 & 0 & 1 & 1 \\
\hline Greater difficulty with primary care linkages & 4 & 4 & 0 & 2 & 2 \\
\hline Difficulty for patients in navigating system of care & 11 & 9 & 2 & 6 & 5 \\
\hline Greater delays in care & 6 & 5 & 1 & 4 & 2 \\
\hline Poorer access and lower quality of care & 7 & 6 & 1 & 3 & 4 \\
\hline Workforce and training changes & 15 & 14 & 1 & 8 & 7 \\
\hline Loss of training sites and faculty & 10 & 9 & 1 & 6 & 4 \\
\hline Workforce relocated & 8 & 7 & 1 & 4 & 4 \\
\hline No impact & 14 & 2 & 12 & 4 & 10 \\
\hline
\end{tabular}

Notes: Values are numbers of physicians. Numbers were tabulated from the total number of physicians who stated a quotation within the theme or subtheme.

Overall, 24 of interviewed physicians (57\%) throughout the region noted a decrease in the system's capacity that they attributed to the hospital's closure (Table 3). The strain on the region's resources was experienced more acutely by physicians working in underserved settings, but a third of physicians who reported this theme worked in a nonunderserved setting. Geographically, the effects were more common for physicians closer to the closed hospital, but changes to the system's capacity were also evident more than 20 miles away.

Physicians described how the closure of the public hospital's subspecialty clinics overwhelmed an already strained local system, particularly for specialty referrals. One physician noted how limited specialty consultations were: "Specialty care has been reduced to $25 \%$, so there's only 2 specialties now" [pediatrician, underserved setting]. Similarly, referrals for elective surgeries were made increasingly difficult by the closure of the hospital's operating rooms. As a physician explained, "Elective surgery? It is virtually impossible to get a schedule. The wait lists are just insane" [family physician, underserved setting]. Often these referrals for specialists and surgeries were sent to distant safety-net hospitals because of availability and insurance coverage $e_{\text {; }}$ however, some physicians noted when their patients became sick enough, they would go to emergency departments and receive this advanced specialty care there.
The loss of direct admission privileges to hospital beds required sending patients through emergency departments, thus worsening continuity of care between the physicians and their patients. Because of the prolonged time until admission and the greater distance to the admitting hospital, physicians noted that they were unable to follow some patients and lost them from their primary care panel: "The system isn't allowing them to get into a [hospital] bed, then you end up losing the patient..." [family physician, underserved setting].

Increased overcrowding of emergency departments was also frequently described. One physician offered the following assessment:

So this particular area has a lot of needs for emergency services as well as trauma... So those particular problems that you have now is that those patients, you have to call 911 in order for them to come and get those kids, as well as adults, who are significantly having difficulty in terms of emergency care, because urgent care can't handle it [family physician, underserved setting].

Crowding of emergency departments throughout the region was the most prominent change described by physicians who practiced outside the MLK Hospital system as noted here: "So there is a ripple effect. I mean the immediate effect is the hospitals right in the area, but as they get backed up people just go to the next one" [internist, nonunderserved setting]. 
Theme 2: Patient Difficulty Navigating System of Care

Physicians described the detrimental effect that the public hospital closure had on patient care. Of the 11 physicians $(26 \%)$ who mentioned this theme, $85 \%$ worked in underserved settings (Table 3). Physicians reported seeing sicker patients, which several attributed to patients delaying care for various reasons including poor awareness of changes in access and lack of transportation to cover the increased distance. One physician mentioned:

...uninsured patients [are] heavily reliant on the safetynet hospitals, particularly the public hospitals... We do see more emergency surgeries on uninsured patients here because they're waiting in that queue and they have cholelithiasis and then they get the acute attack where they have to have the emergency surgery [internist, underserved setting].

At the time MLK Hospital closed, the transitional plan was for the hospital's affiliated ambulatory care clinics to remain open and gradually increase services and capacity, while the inpatient, subspecialty, and emergency services would transition to neighboring safetynet medical centers. The interviewed physicians noted substantial confusion for patients in identifying the appropriate site and level of care. One internist believed this confusion disrupted his continuity of care: "... slowly we've been getting our patients back to the outpatient clinics, but it's taken a while to do that because of the perception in the community that [clinics are closed] out there" [internist, underserved setting].

These physicians also perceived that the transfer of care throughout the safety-net system failed and consequently, the patients fell back on the overwhelmed system. As described by one: "So you have the patients come in every 30 days for a prescription refill through the emergency room for their antihypertensive.... If you're not really, really sick, we can't put you in a primary care clinic because there aren't any" [internist, underserved setting].

\section{Theme 3: Workforce and Training Changes} Several physicians described how the closure of the academic teaching hospital affected educators and trainees within the safety net. This theme predominantly affected physicians who worked within the network of the closed safety-net hospital, and the quotations conveyed a sense of strain secondary to the closure. Fifteen $(36 \%)$ of the interviewed physicians described the impact on workforce and educational training opportunities about workforce retention within the safety net (Table 3). Eight physicians described physician workforce losses that started with gradual attrition of faculty from training programs at MLK Hospital in the years before closure from multifactorial causes including pro- ductivity concerns, residency accreditation losses, and finally loss of hospital accreditation resulting in the loss of the remaining residency programs at the time of closure. Of note, some of the changes related to residency program closure occurred in the years before closure; however, physicians echoed the sentiments of one of their colleagues, who stated that:

...because of the losses of hospitals and closures, many physicians are leaving, a lot are leaving the community, and many are leaving the state of California period...those physicians who were key to the community are no longer available [family physician, nonunderserved setting]

Another primary care physician described the loss of committed physicians after hospital closure as "a huge exodus. Charles Drew University's faculty, the practicing faculty completely disappeared. They were attracted to other hospitals that had ready and waiting suites to practice in. I don't think anybody appreciated... how valuable that medical staff was..." [family physician, underserved setting].

Additionally, 10 physicians noted that fewer residents had opportunities to learn in underserved settings as training slots were shifted from closed programs to other regional programs.

\section{Themes by Practice Setting and Proximity to the Hospital}

Of the 24 physicians who reported worsened health care system capacity after hospital closure (Table 3), the majority worked in underserved settings. Physicians in the underserved settings were more likely to endorse subthemes related to changes in the local hospital service area, changes in workforce and training, and difficulty for patients navigating the system of care. Physicians in nonunderserved settings were more likely to describe no impact from hospital closure.

Physicians who worked closer to the closed hospital were more likely to describe a change to the local and regional health care system: 14 of 17 physicians within a 12 -mile radius vs 10 of 25 physicians farther away (Table 3). Substantially more physicians who worked 12 miles or less from the closed hospital described themes about emergency department overcrowding. By distance, similar numbers of physicians in local areas vs nonlocal areas described patient difficulty navigating the system (6 vs 5 physicians) and workforce changes (8 vs 7 physicians).

\section{DISCUSSION}

This study of physicians in South Los Angeles after the closure of MLK Hospital provides important insights into how the roles and practices of primary care physicians change after a local safety-net hospital closes. A 
majority of the physicians from both underserved and nonunderserved practice settings acknowledged an effect in the year after hospital closure. More than half of the physicians we interviewed reported widespread and noteworthy effects of the hospital's closure on their practices. Contrary to expectations, the impact was felt well beyond practices close to MLK Hospital and extended to those more than 20 miles away. The themes that emerged from these interviews describe a primary care workforce bearing the brunt of patient care without adequate patient care support.

Using 1-on-1 interviews with physicians allowed us to explore the changes to physician practices, system capacity, and patient behaviors, and illuminate the systemwide disruption caused by a safety-net hospital closure from the primary care perspective. Previous studies have focused on documenting differences in patient outcomes from administrative or survey data. ${ }^{5,6}$ Other studies have focused on changes due to distance traveled, ${ }^{12-14}$ rural hospital closure, ${ }^{15-20}$ and staffing changes. ${ }^{21-23}$

The overburdened system and resulting delays in care were acutely apparent to many of the physicians we interviewed but were the product of different mechanisms at the local and regional levels. Those physicians who practiced farther away were more likely to describe a strain on their resources from the influx of patients who formerly received their care within the safety-net hospital system. The personal and professional strain identified was related to the changes in workforce and teaching opportunities. For the academic clinicians, the loss or diminution of their teaching role and the loss of colleagues who left the area had a clear career and personal impact.

There are some limitations to our analysis. Although useful for identifying exploratory themes, semistructured interviews are sensitive to respondent and researcher bias because of the qualitative nature of the data. We worked to mitigate these potential problems through multiple independent reviews of the data by different members of the study team. Our study was shaped by our research team's hypotheses and the CAB's input a priori to data collection. Additionally, the physicians interviewed were not chosen at random, but through a recruitment process heavily influenced by the board. Our CAB members were extremely concerned about the loss of physicians from the community and whether they would be able to recruit more physicians back to the community. As the first wave of physicians referred others, our interviewed participants may have had similar views to the initial group of physicians interviewed. Additionally, the preconceptions and views of our participants may have been from those who had particular views. For these reasons, the full range of issues after hospital closure may not have been elucidated. Because of these preconceptions, the experiences reported in Los Angeles County in the first year after closure may not generalize to other urban areas with different geographic and health care system characteristics. We realize that some additional safetynet hospitals are located within the 12 -mile radius. Two additional public hospitals are within a 10 -mile radius of the closed hospital, but because of geographic barriers and traffic congestion in Los Angeles County, it can take upward of an hour to travel 5 miles in the direction of the other hospitals. This particular issue with regular traffic congestion is not unfamiliar to other metropolitan cities; however, it may be particular to Los Angeles' travel patterns. In addition, our goal in this study was not to account for the confounding events that may have occurred elsewhere in the system, rather, we wanted to explore the impact of hospital closure for primary care physicians. Although our sample was nonrepresentative, our themes quickly reached saturation with this group of physicians from diverse clinic settings.

Our findings will inform ongoing planning to improve the safety net's ability to coordinate health care services when the hospital reopens (currently planned for late 2012). Primary care physicians should be informed and consulted when a major disruption to the health care delivery system is planned. Physicians in both safety-net systems and non-safety-net systems were affected and could provide additional input to the planning process. Although consistent themes about recommended next steps did not emerge and were beyond the scope of this work, the physicians did question the approach to planning after hospital closure. They were concerned about addressing community perceptions, improving handoffs, and creating systematic assessments of ambulatory care in a way that improves efficiency and decreases redundancies. In the first year after hospital closure, physicians and patients alike experienced poor coordination and fragmentation of care, and difficulty accessing needed services. As our findings are relevant to the first year after closure, the $\mathrm{CAB}$ members and their respective organizations are working to ensure that the increased strain on patients and physicians improves over time.

Although health care reform may extend insurance coverage, it may still leave out certain populations, particularly in states with large numbers of undocumented immigrants. Safety-net hospitals will thus continue to serve a vital stop-gap role for those who do not meet coverage criteria for Medicaid, Medicare, and other targeted programs. Primary care clinicians in the safety net will still be on the front line for addressing preventive care, chronic illness, and urgent health care needs. Future studies should also examine whether the presence of a medical home for poor, uninsured, 
and underserved populations enhances the ability of patients, clinicians, and the health care system as a whole to overcome such disruptions.

In conclusion, although research has long suggested that the closure of a large urban hospital changes the practice patterns not only for inpatient services but also in terms of patient experiences, our study suggests that primary care physicians in the region also experience profound clinical, professional, and personal upheaval. The physicians we interviewed described challenges with the loss of local services, greater delays in and poorer quality of care for patients, multiple disruptions in the network of care for patients in the safety-net system, and increased workforce strain. It is important to anticipate and address these challenges, particularly as safety-net hospitals and primary care physicians work to create an effective medical home to improve quality of care for underserved and uninsured populations.

To read or post commentaries in response to this article, see it online at http://www.annfammed.org/content/9/6/496.

Key words: Hospital closure; physician perspective; delivery of health care; practice-based research; safety net; primary care; community advisory board

Submitted January 12, 2011; submitted, revised, July 28, 2011; accepted August 8, 2011.

Funding support: Dr Walker received funding from the Robert Wood Johnson Foundation Clinical Scholars Program at UCLA and the UCLA Resource Center for Minority Aging Research/Center for Health Improvement of Minority Elderly under the National Institutes of Health/ National Institute on Aging (grant P30AG021684) and the UCSF Center for Aging in Diversity Communities (grant P30AG015272). Dr Brown received support from the Beeson Career Development Award (K23 AG26748), the UCLA Resource Center in Minority Aging Research (grant AG02004), and the National Center on Minority Health and Health Disparities (grant P2OMD00148).

Acknowledgments: We would like to acknowledge our $C A B$ members, including Charles Drew University, Community Clinic Association of Los Angeles, Los Angeles County Department of Health Services, and Healthy African American Families, Los Angeles County Medical Association, Latino Medical Policy Institute, and Region VI of the National Medical Association. We would also like to thank Robin Ramey, MS, Trudy Singzon, MD, MPH, and Sharon L. Hayes for their assistance with data collection and preparation.

This work was previously presented in part in a poster presentation titled The Ripple Effect of Hospital Closure: Primary Care Physicians View of the Healthcare System, Physician Workforce and Patient Care, given at the Society of General Internal Medicine meeting, Minneapolis, Minnesota, April 29, 2010.

\section{References}

1. Hasnain-Wynia R, Baker DW, Nerenz D, et al. Disparities in health care are driven by where minority patients seek care: examination of the hospital quality alliance measures. Arch Intern Med. 2007;167(12):1233-1239.
2. Jha AK, Orav EJ, Li Z, Epstein AM. Concentration and quality of hospitals that care for elderly black patients. Arch Intern Med. 2007;167(11):1177-1182.

3. Lewin ME, Altman SH, Institute of Medicine. Committee on the Changing Market Managed Care and the Future Viability of Safety Net Providers. America's Health Care Safety Net: Intact But Endangered. Washington, DC: Institute of Medicine, National Academy Press; 2000.

4. Goldman LE, Vittinghoff E, Dudley RA. Quality of care in hospitals with a high percent of Medicaid patients. Med Care. 2007;45(6): 579-583.

5. Bindman $A B$, Keane $D$, Lurie N. A public hospital closes. Impact on patients' access to care and health status. JAMA. 1990;264(22): 2899-2904.

6. Buchmueller TC, Jacobson M, Wold C. How far to the hospital? The effect of hospital closures on access to care. J Health Econ. 2006; 25(4):740-761.

7. Whiteis DG. Hospital and community characteristics in closures of urban hospitals, 1980-87. Public Health Rep. 1992;107(4):409-416.

8. Williams D, Hadley J, Pettengill J. Profits, community role, and hospital closure: an urban and rural analysis. Med Care. 1992;30(2):174-187.

9. Audet AM, Doty MM, Shamasdin J, Schoenbaum SC. Measure, learn, and improve: physicians' involvement in quality improvement. Health Aff (Millwood). 2005;24(3):843-853.

10. Goldman LE, Henderson S, Dohan DP, Talavera JA, Dudley RA. Public reporting and pay-for-performance: safety-net hospital executives' concerns and policy suggestions. Inquiry. 2007;44(2):137-145.

11. New Jersey Hospital Association Health Planning Department. Hospital Closure Guidelines: Best Practices from the Field. First Edition. 2008. http://www.njha.com/Publications/Pdf/Hospital_ Closure_Guidelines.pdf. Accessed Nov 30, 2010.

12. Currie J, Reagan P. Distance to Hospital and Children's Access to Care: Is Being Closer Better, and for Whom? Cambridge, MA: National Bureau of Economic Research; 1998.

13. Goodman DC, Fisher E, Stukel TA, Chang C. The distance to community medical care and the likelihood of hospitalization: is closer always better? Am J Public Health. 1997;87(7):1144-1150.

14. Lamont EB, Hayreh D, Pickett KE, et al. Is patient travel distance associated with survival on phase II clinical trials in oncology? J Natl Cancer Inst. 2003;95(18):1370-1375.

15. Barnett $R$, Barnett $P$. "If you want to sit on your butts you'll get nothing!" Community activism in response to threats of rural hospital closure in southern New Zealand. Health Place. 2003;9(2):59-71.

16. Mayer JD, Kohlenberg ER, Sieferman GE, Rosenblatt RA. Patterns of rural hospital closure in the United States. Soc Sci Med. 1987;24(4):327-334.

17. Muus KJ, Ludtke RL, Gibbens B. Community perceptions of rural hospital closure. J Community Health. 1995;20(1):65-73.

18. Ozcan YA, Lynch JR. Rural hospital closures: an inquiry into efficiency. Adv Health Econ Health Serv Res. 1992;13:205-224.

19. Reif SS, DesHarnais S, Bernard S. Community perceptions of the effects of rural hospital closure on access to care. J Rural Health. 1999;15(2):202-209.

20. Rosenbach ML, Dayhoff DA. Access to care in rural America: impact of hospital closures. Health Care Financ Rev. 1995;17(1):15-37.

21. Havlovic SJ, Bouthillette F, van der Wal R. Coping with downsizing and job loss: lessons from the Shaughnessy Hospital closure. Canad J Admin Sci. 1998;15(4):322-332.

22. Mesch DJ, McGrew JH, Pescosolido BA, Haugh DF. The effects of hospital closure on mental health workers: an overview of employment, mental and physical health, and attitudinal outcomes. J Behav Health Serv Res. 1999;26(3):305-317.

23. Petchers MK, Swanker S, Singer MI. The hospital merger: its effect on employees. Health Care Manage Rev. 1988;13(4):9-14. 